\title{
COMPARISON OF EARLY POSTOPERATIVE RESULTS OF ON-PUMP VERSUS OFF-PUMP CORONARY BYPASS GRAFTING SURGERY
}

Waheed Etman, Mostafa Agha, Wael Hassanein, Wael Shaalan,* Hanan Mamdouh Hemead

Department of Cardiothoracic Surgery, Department of Vascular Surgery, * Alexandria University, Alexandria, Egypt

\section{Introduction}

Assisted by cardiopulmonary machine (CPB), CABG surgery is performed safely with excellent outcomes. Due to the adverse events linked to the CPB, the off-pump CABG becomes an acceptable alternative particularly in patients with calcified proximal aorta. Critics of off-pump CABG often refer to the long learning curve and difficult building cumulative surgical experience. Off-pump CABG has been always a matter of debate. Off-pump CABG becomes highly appealing due to minimal outcomes.

\section{Aim of the work}

This study evaluates the early postoperative outcomes of off-pump CABG compared to on-pump CABG.

\section{Subjects and Methods}

First eligible comers in the period between 2018-2019.The following points were compared between the two groups Amount of bleeding, length of stay, duration of mechanical ventilation, operative time, completion of revascularization, complications; atrial fibrillation, neurological deficits, acute kidney injury.

\section{Results}

Table1: Comparison of Postoperative Outcomes in Both Groups

\begin{tabular}{||llc|c|c|c} 
& Groups & N & Mean & Std. Deviation & P value \\
\hline Bleeding (ml) & on-pump & 40 & 554.25 & 256.164 & $<0.001$ \\
\cline { 2 - 5 } & off-pump & 40 & 380.0 & 106.069 & \\
\hline Length of Stay in ICU (Days) & on-pump & 40 & 5.23 & 2.616 & \multirow{2}{*}{$<0.001$} \\
\cline { 2 - 5 } & off-pump & 40 & 3.68 & .526 & \\
\hline \multirow{2}{*}{ Mechanical ventilation (hour) } & on-pump & 40 & 10.73 & 15.317 & \multirow{2}{*}{0.005} \\
\cline { 2 - 5 } & off-pump & 40 & 4.50 & .679 & \\
\hline
\end{tabular}

Table2: Incidence of Postoperative Complications in Each Group
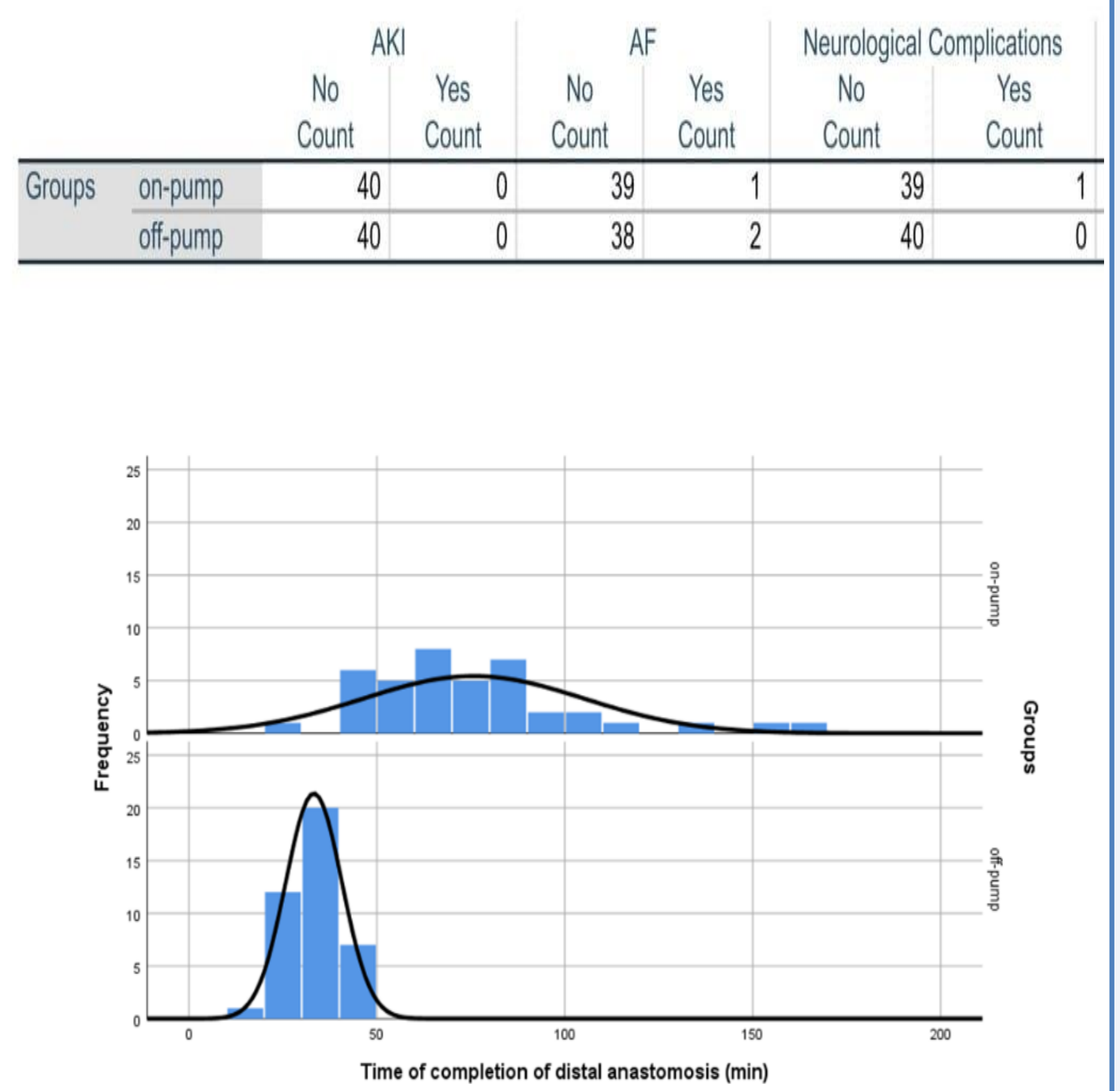

Figure 1: Comparison of the time needed to complete distal anastomoses in Both Groups

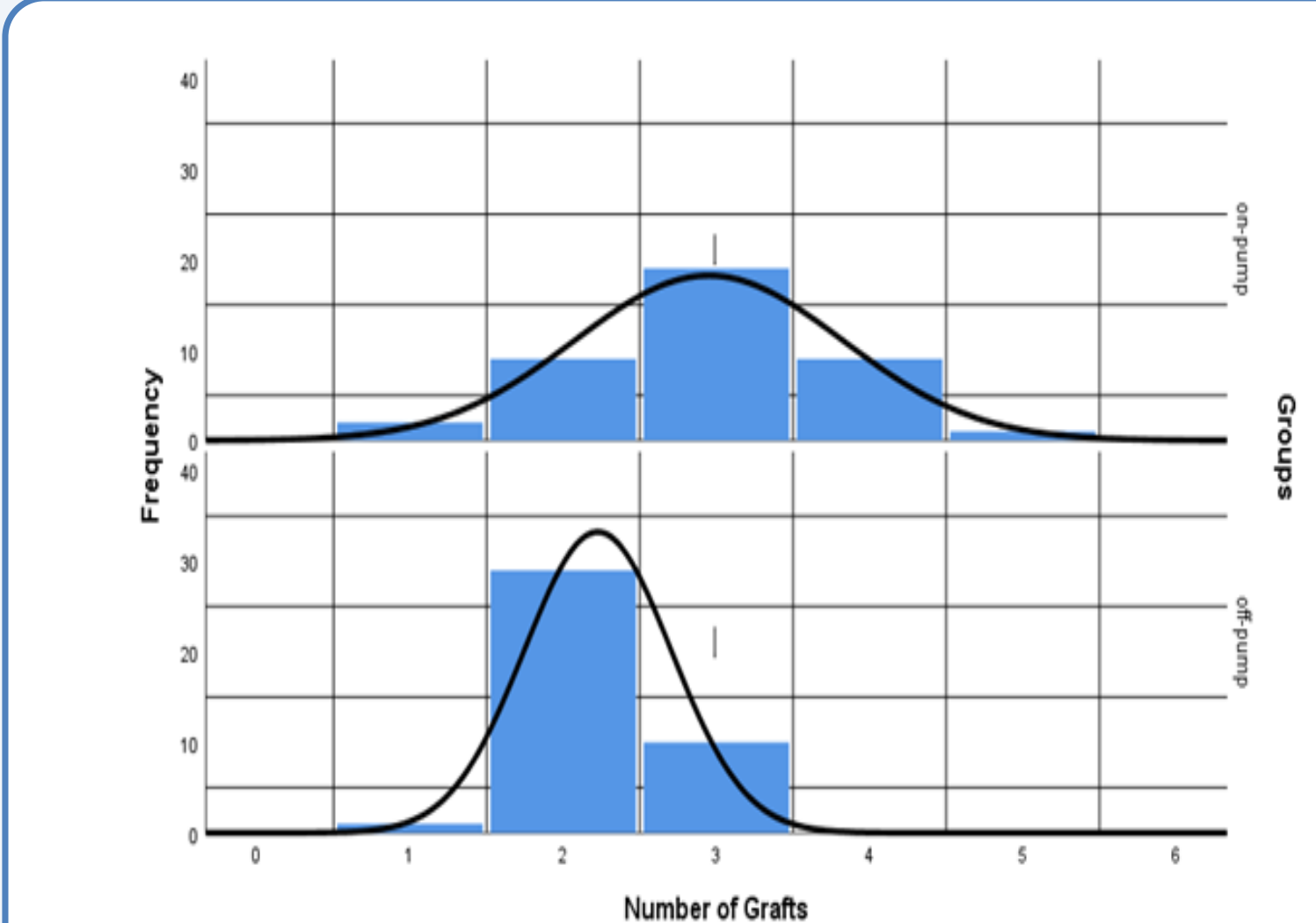

Number of Grafts

Figure 2: Comparison of number of grafts in both groups

\section{Conclusion}

The argument surrounding the potential advantages and safety of the offpump is difficult to be settled. Off-pump CABG, in the hands of trained surgeons, offers favorable short-term outcomes particularly in patients with complex co-morbidities. It is highly indicated in heavily calcified aorta to avoid the thromboembolic events. The decision should be made on individual basis, taking into consideration the potential long-term adverse outcomes. 